\author{
Petro Topilnytsky and Victoria Romanchuk
}

\title{
IN VESTIGATION OF REAGENTS WITH DIFFERENT CHEMICAL COMPOSITIONS FOR PROTECTION OF OIL PRIMARY REFINING EQUIPMENT
}

\author{
Lviv Polytechnic National University,
} 12 Bandery str., 79013 Lviv, Ukraine

Received: November 12, 2009 / Accepted April 09, 2010

(C) Topilnytsky P., Romanchuk V., 2010

\begin{abstract}
The article deals with the investigation results of nitrogen-containing compounds solubility in non-polar and polar solvents, as well as low-temperature properties of formed solutions and their anticorrosive properties as corrosion inhibitors in the hydrocarbon-water two-phase system.
\end{abstract}

Keywords: corrosion, corrosion prevention, corrosion inhibitors, carbazolines, solvents, solubility.

\section{Introduction}

Corrosion is a physico-chemical or chemical interaction between metal and medium resulting in the degradation of metal and medium functional properties. The corrosion main factors are: metal type, temperature, liquid composition, liquid rate, acidity and gases content.

All processes of oil refining take place under the influence of high temperatures, pressures and chemical reagents of different corrosiveness. Under mentioned conditions the crude oil ingredients decompose and transform with the formation of chemical products of different nature and corrosiveness. Thus, petroleum, which is low-corrosive or non-corrosive at ambient temperatures, acquires properties of corrosive medium.

Usually the crude oil is supplied at a refinery with the content of water from 0.2 to $1 \%$. It also contains such dissolved salts as calcium ( $10 \%)$, magnesium $(\sim 20 \%)$ and sodium/potassium $(\sim 70 \%)$ chlorides [1]. The aggressive hydrogen chloride is formed at heating crude oil which results in chlorides hydrolytic decomposition:

$$
\begin{gathered}
\mathrm{MgCl}_{2}+2 \mathrm{H}_{2} \mathrm{O} \rightarrow \mathrm{Mg}(\mathrm{OH})_{2}+\mathbf{2 H C l} \\
\mathrm{CaCl}_{2}+2 \mathrm{H}_{2} \mathrm{O} \rightarrow \mathrm{Ca}(\mathrm{OH})_{2}+2 \mathrm{HCl}
\end{gathered}
$$

Under the conditions of oil primary refining the essential hydrolysis of dissolved $\mathrm{MgCl}_{2}$ begins at $\sim 393 \mathrm{~K}$ and 0.4-0.5 $\mathrm{MPa}$. The growth of temperature intensifies the hydrolysis [2].
Values of $\mathrm{pH}$ essentially influence the corrosion rate. The acid medium (low $\mathrm{pH}$ values) increases the rate and the reduction of medium acidity (high $\mathrm{pH}$ values) decreases it.

Sulfur-containing compounds of oil are the main reasons of the equipment corrosion attack. Hydrogen sulfide is the corrosion agent at almost all stages of oil primary and destructive refining $[1,2]$. In humid media with hydrogen sulfide the conditions for metal hydrogenation are formed. It has been established that hydrogen sulfide is a strong promoter of hydrogen penetration into metal. Even at low rates of electrochemical corrosion it may cause the strong metal hydrogenation. To explain the reasons of metal brittleness under the influence of sulfur, the conception concerning $\mathrm{H}_{2} \mathrm{~S}$ and $\mathrm{HS}^{-}$adsorption is used. According to this conception, the bond between surface atoms weakens facilitating hydrogen penetration into metal. $\mathrm{H}_{2} \mathrm{~S}$ and $\mathrm{HS}^{-}$are characterized by high adsorptive and catalytic activity during metal ionization and cathodic reduction of $\mathrm{H}^{+}$ions. In alkali media particles of $\mathrm{H}_{2} \mathrm{~S}, \mathrm{HS}^{-}$and $\mathrm{S}^{2-}$ may be displaced by $\mathrm{OH}^{-}$ions due to the competitive adsorption [2].

Hydrochloric and hydrogen-sulfide corrosions take place at the plant of oil primary refining. Heat exchangers, condensers, reservoirs, upper part of the columns and vapor lines are the main objects of corrosion [3].

The following precautions are fulfilled in order to prevent corrosion of the refinery equipment:

1. Oil demineralization means extraction of chloride salts out of oil by washing with fresh water and using of surface-active components - demulsifiers.

2. Alkalization of raw material. $\mathrm{NaOH}$ or $\mathrm{Na}_{2} \mathrm{CO}_{3}$ which act as neutralizers are added to the crude oil before or after its dehydration for chemical interaction between neutralizers and chloride salts hydrolysis products.

3. Neutralization of atmospheric column overheads means chemical interaction with hydrogen chloride escaping during chloride salts hydrolysis. Non-organic and 
organic compounds with high basic properties are used as neutralizers.

4. Corrosion inhibitors. As a rule they are surface active agents forming a protective film over metal surface which protects the metal from the aggressive medium $[4,5]$.

In most cases inhibitors which are used in oilrefining industry are polar or non-polar organic substances, the molecules of which consist of hydrocarbon radical bonded with a functional group which contains nitrogen, oxygen, sulfur or other atoms [5]. In order to improve inhibitor properties the modification takes place: definite functional groups are introduced into the molecule. Such groups influence the properties of obtained compounds. The inhibitor protective action is determined by the formation of continuous adsorptive nonwettable layer (nonwettable films over metal surface are formed due to adsorption of inhibitor molecules), which reduce the admission of medium aggressive components to metal. Polar group of inhibitor molecule causes the appearance of cohesion between metal atoms and inhibitor molecules. Inhibitor adsorbed molecules are turned to the side of the solution forming a hydrophobic layer, where adsorption of another layer of hydrocarbon molecules (if they are present in corrosive medium) may take place [6].

The aim of present work is to study soluble ability, low-temperature properties of nitrogen-containing compounds and investigation of their anticorrosive properties as corrosion inhibitors in the hydrocarbon-water two-phase system.

\section{Experimental}

\subsection{Objects}

In order to select high-effective inhibitor for refinery equipment for the first time we studied imidazoline derivatives, cationic fats, esters of bur oil acids and amides of polyaminonaphthenic acids. The change of several fragments of the complex inhibitor may strengthen definite properties corresponding to the definite conditions under which the inhibitor would be used. This aim may be achieved by introduction of definite functional groups into inhibitor molecule.

The optimization of chemical composition of inhibitor active substance has been realized in the following way:

- by selection of acid fragment;

- by selection of polyamine fragment;

- by regulation of lipophily using oxyethylation.

Oleic and stearic acids are used as acid fragments and diethylenediamine, diethylenetriamine, pentaethylenetriamine, diethanolamine, triethanolamine and others are used as polyamine component for imidazoline derivatives. Changing the oxyethylation degree (amount of moles of introduced ethylene oxide) we may change hydrophility of active substance molecule. The oxyethylation degree is $1-2$.

A. Alkylimidazoline derivatives on the basis of stearic acid (S) are the dopes of the color from white to yellow tint with nitrogen mass part from 7 to $14 \%$.

\section{Carbazoline ST-4}

1-(5-amino-3-aza-pentyl)-2-heptadecyl-2-imidazoline nitrogen mass part $\mathrm{N}=14.2 \%$

\section{Carbazoline SD-3}

1-(2-aminoethyl)-2-heptadecyl-2-imidazoline nitrogen mass part $\mathrm{N}=12 \%$

\section{Carbazoline SB}

1-(2-hydroxyethyl)-2-heptadecyl-2-imidazoline nitrogen mass part $\mathrm{N}=8 \%$

\section{Carbazoline SB-2}

1-(6-hydroxy-3-oxapentyl)-2-heptadecyl-2-imidazoline nitrogen mass part $\mathrm{N}=7 \%$
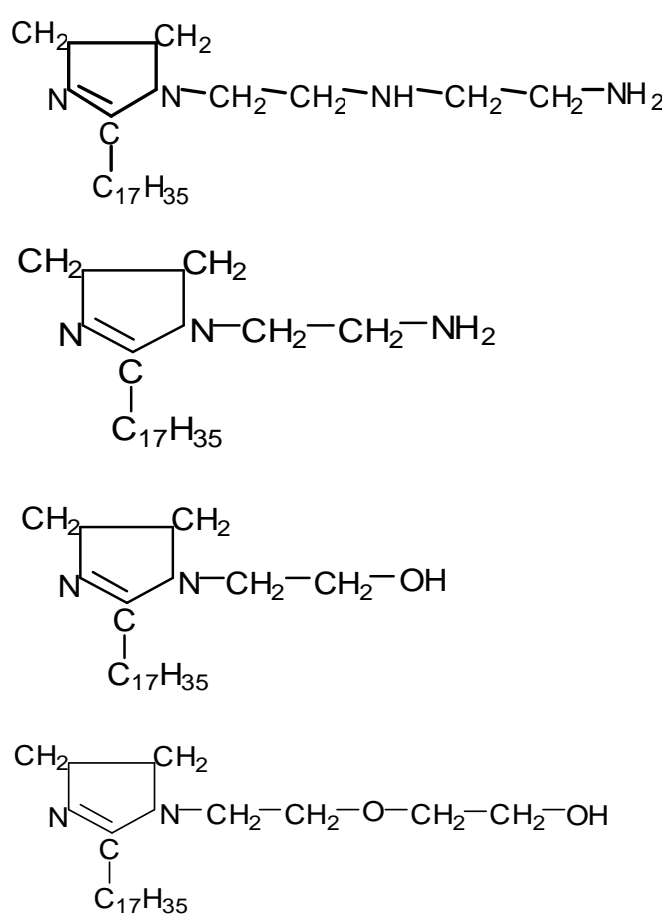
B. Alkylimidazoline derivatives on the basis of oleic $(\mathrm{O})$ acid are transparent oily liquids with ammoniac smell of the color from yellow to dark-yellow tint with nitrogen mass part from 8 to $12 \%$.

\section{Carbazoline OD-3}

1-(2-aminoethyl)-2-heptadecenyl-2-imidazoline nitrogen mass part $\mathrm{N}=12 \%$

\section{Carbazoline OT-2}

1-(2-diethanolaminoethyl)2-(8-heptadecenyl )-2-imidazoline nitrogen mass part $\mathrm{N}=9.6 \%$<smiles>CC1=NCCN1CCN</smiles>

\section{Carbazoline OB}

1-(2-hydroxyethyl)-

2- (8-heptadecenyl)-2-imidazoline nitrogen mass part $\mathrm{N}=8 \%$
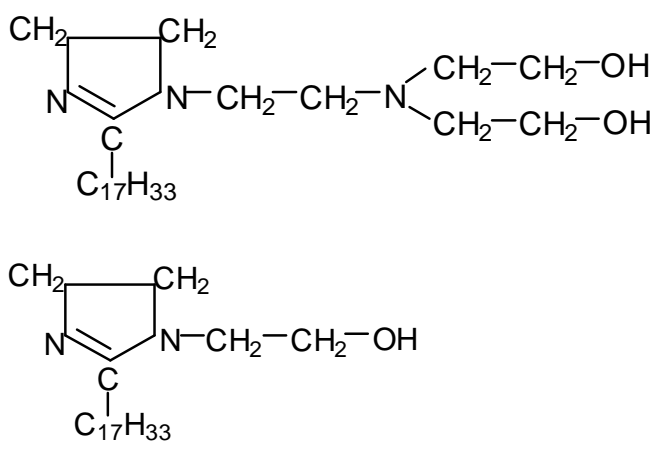

C. Esters of bur oil acids. Bur oil contains prior to $7 \%$ of saturated acids and $93 \%$ of unsaturated ones.

\section{Carbazoline RT-2}

1-(2-diethanolaminoethyl)-2-(2-R)-2-imidazoline nitrogen mass part $\mathrm{N}=9.3 \%$

$$
\begin{aligned}
& \text { where } \quad \begin{array}{l}
\mathrm{R}_{1}=\mathrm{C}_{\mathrm{n}} \mathrm{H}_{2 \mathrm{n}+1} \\
\mathrm{R}_{2}=\mathrm{C}_{\mathrm{n}} \mathrm{H}_{2 \mathrm{n}-1} \quad \mathrm{n}=\mathrm{C}_{15}-\mathrm{C}_{21} \\
\mathrm{R}_{3}=\mathrm{C}_{\mathrm{n}} \mathrm{H}_{2 \mathrm{n}-3}
\end{array} \\
& \text { N }
\end{aligned}
$$

\section{Carbazoline RB}

1-(2-hydroxyethyl)-2-R-2-imidazoline nitrogen mass part $\mathrm{N}=7.7 \%$

$$
\begin{aligned}
& \mathrm{R}_{1,2,3} \\
& \mathrm{R}_{1}=\mathrm{C}_{\mathrm{n}} \mathrm{H}_{2 \mathrm{n}+1} \\
& \mathrm{R}_{2}=\mathrm{C}_{\mathrm{n}} \mathrm{H}_{2 \mathrm{n}-1} \quad \mathrm{n}=\mathrm{C}_{15}-\mathrm{C}_{21} \\
& \mathrm{R}_{3}=\mathrm{C}_{\mathrm{n}} \mathrm{H}_{2 \mathrm{n}-3}
\end{aligned}
$$

D. Cationic fat R-1 and RT-3 are as corrosion inhibitors.

1. Cationic fat R-1 (nitrogen content $6 \%$ ) is the mix of the following three products: $\mathrm{N}, \mathrm{N}$ - disubstituted amides

$$
\begin{gathered}
\mathrm{R}\left({ }_{1,2}, 3\right)-\underset{\|}{\mathrm{C}}-\mathrm{N}-\left(\mathrm{CH}_{2}\right)_{2}-\mathrm{NH}-\left(\mathrm{CH}_{2}\right)_{2}-\mathrm{OH} \\
\mathrm{O} \quad \mathrm{CH}_{2}-\mathrm{CH}_{2}-\mathrm{OH}
\end{gathered}
$$

esters of bur oil acids

$$
\begin{array}{cl}
\mathrm{R}\left(1_{1,2,3}\right)- & \mathrm{C}-\mathrm{O}-\left(\mathrm{CH}_{2}\right)_{2}-\mathrm{NH}-\left(\mathrm{CH}_{2}\right)_{2}-\mathrm{NH}-\left(\mathrm{CH}_{2}\right)_{2}-\mathrm{OH} \\
\mathrm{O} & \\
\text { where } & \begin{array}{l}
\mathrm{R}_{1}=\mathrm{C}_{\mathrm{n}} \mathrm{H}_{2 \mathrm{n}+1} \\
\mathrm{R}_{2}=\mathrm{C}_{\mathrm{n}} \mathrm{H}_{2 \mathrm{n}-1} \quad \mathrm{n}=\mathrm{C}_{15}-\mathrm{C}_{21} \\
\mathrm{R}_{3}=\mathrm{C}_{\mathrm{n}} \mathrm{H}_{2 n-3}
\end{array}
\end{array}
$$

and glycerine. 
2. Cationic fat RT-3 (nitrogen amount is $4 \%$ ) is a mix of two products: esters of bur oil acids

and glycerine.

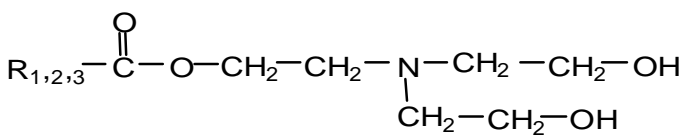

E. Amides of polyaminonaphthenic acids (APANA) by the following formula:<smiles>C[C@H](N)CC1CCC(N)C(CC(N)=O)C1N</smiles>

\subsection{Procedure}

Since solubility and solvents behaviour at low temperatures are the main characteristics of corrosion inhibitors we investigate the solubility of the mentioned compounds in:

- oil solvents: Nefras P-1 and Nefras S-2 which are the mix of alkane row hydrocarbons boiling within the range of 338-348 K and 353-393 K, correspondingly;

- white spirit, boiling within the range of 423-473 K. It contains arenes in the amount of $25 \%$;

- oil solvent which is a mix of aromatic hydrocarbons (ethylbenzene and xylenes);

- jet fuel - mix of highmolecular alkane-, cycloalkane- and arene hydrocarbons;

- individual aromatic hydrocarbons: benzene and toluene;

- polar solvents: methyl and isopropyl alcohols;

- water is used for comparison.

Inhibitor $(50 \mathrm{ml})$ is placed into a conic flask by the volume of $250 \mathrm{~cm}^{3}$, then $50 \mathrm{ml}$ of solvent is added and the whole mix is stirred. The dilution is carried out first at room temperature $(293 \mathrm{~K})$; then solutions are heated to $323 \mathrm{~K}$ under shaking. The obtained solution should be transparent. If the inhibitor fully mixes with the solvent and sludge does not precipitate during $1 \mathrm{~h}$, then the inhibitor passes the test.

Obtained solutions are withdrawn into test-tubes in amount of $20 \mathrm{ml}$ and cooled to $283 \mathrm{~K}$ using water bath or to $258 \mathrm{~K}$ using refrigerator. If the solution meniscus is not changed at tube inclination by $45^{\circ}$, the solution freezes.

\section{Results and Discussion}

It has been established that solubility depends upon chemical composition of investigated substance, solvent nature (polarity), molecular mass and freezing point. Since a bulk of data concerning solubility is huge, they are not presented in this paper.
Non-ethylated and ethylated carbazolines based on stearic acid do not dissolve in polar solvents (solvent, white spirit and toluene) at room temperature and form cloudy solutions at high temperatures and stirring. At cooling to $283 \mathrm{~K}$ solutions become denser, sometimes with sludging, and freeze at lower temperature.

Carbazolines based on stearic acid practically do not dissolve in non-polar solvents (Nefras P-1 and S-2) and jet fuel even at high temperatures or form cloudy solutions. Such poor solubility of carbazolines based on saturated stearic acid $\left(\mathrm{C}_{17} \mathrm{H}_{35} \mathrm{COOH}\right)$ may be explained by poor solubility of stearic acid as itself in all investigated solvents. Thus, solubility of stearic acid ( $\mathrm{g}$ for $100 \mathrm{~g}$ of solvent) is: 2.4 in benzene; 6.0 in chloroform; 2.25 in ethanol; 0.12 in $\mathrm{CH}_{3} \mathrm{COOH}$ and 0.03 in water. Branching and length of the side chain as well as molecular mass does not affect carbazolines solubility.

Carbazolines on the basis of unsaturated oleic acid dissolve better in polar solvents: OD-3 and OT-2 form transparent solutions already at room temperature. Oxyethylated carbazoline OB (oxyethylation degree is 1) dissolves worse compared with OT-2 (oxyethylation degree is 2). Carbazoline OB is sufficiently viscous, so the longer stirring or short-term heating to $323 \mathrm{~K}$ is needed. Moreover, carbazoline OB has the less branched structure in its side chain and less molecular mass. This fact has a negative influence on carbazoline solubility.

Carbazolines based on oleic acid dissolve better in oil solvents (Nefras P-1 and S-2) and jet fuel already at room temperature compared with those on the basis of stearic acid.

Carbazoline RB (esters of bur oil acids with oxyethylation degree equaled to 1 ) in contrast to carbazoline RT-2 (oxyethylation degree is 2) dissolves better at room temperature in oil solvents but worse in aromatic solvents and alcohols. RT-2 at room temperature under stirring dissolves in white spirit, toluene and alcohols. At heating to $323 \mathrm{~K}$ upon stirring it dissolves in oil solvents and jet fuel. 
Cationic fat RT-3 completely dissolves at room temperature in polar solvents: white spirit, solvent, toluene and isopropyl alcohol with the formation of transparent solutions. Cationic fat R-1 has worse solubility, especially in isopropyl alcohol and aromatic solvents.

Low-temperature properties of obtained solutions at cooling to 283 and $258 \mathrm{~K}$ have been studying because these properties affect the possibility of inhibitor supply at low temperatures.

Cooling of all carbazolines based on stearic acid to $283 \mathrm{~K}$ results in solutions thickening or formation of cloudy solutions (emulsions). SB and SB-2 thicken in solvent and toluene but become cloudy in white spirit, jet fuel, methanol and isopropanol. SD-3 and ST-4 become cloudy in all solvents except isopropyl alcohol.

At $258 \mathrm{~K}$ all carbazolines based on stearic acid are frozen.

Carbazolines on the basis of oleic acid does not practically change their aggregative states at cooling to $283 \mathrm{~K}$.

Solutions of non-ethylated OD-3 in jet fuel at low temperatures $(258 \mathrm{~K})$ segregate forming a bottom emulsion layer. Solutions do not freeze completely at this temperature. If methanol or isopropanol are solvents then a negligible amount of cloudy precipitate is formed. The rest of OD-3 solutions do not freeze at $258 \mathrm{~K}$.

OT-2 solutions do not freeze at mentioned temperature.

In methanol and isopropanol carbazolines OB become cloudy (form emulsions) and freeze at $258 \mathrm{~K}$. Solutions in a solvent, white spirit and toluene thicken and those in Nefras P-1, S-2 and jet fuel completely get sluggish, i.e. freeze.

At $283 \mathrm{~K}$ esters of bur oil acid RB and RT-2 stay transparent while diluting in the solvent, toluene, white spirit, methanol and isopropanol. In Nefras P-1 RB freezes. S-2 thickens in nefras but forms cloudy solution in jet fuel. RT-2 in both mentioned solvents precipitates but does not freeze.

Further cooling of RB to $258 \mathrm{~K}$ leads to solutions freezing in Nefras P-1 and S-2, as well as in white spirit. Segregation takes place in jet fuel and thickening - in methanol and isopropanol. Carbazoline RT-2 does not freeze in nefrases, white spirit and toluene but thicken in form cloudy solution in jet fuel.

At the temperature of $283 \mathrm{~K}$ solutions of R-1, RT-3 cationic fats remain transparent almost in all solvents, and only in jet fuel R-1 precipitates. The decrease of temperature to $258 \mathrm{~K}$ does not change the solutions state.

Amides of polyaminonaphthenic acids have the best solubility. They are soluble in all kinds of solvents except water. At the same time they form transparent solutions already at room temperature. The decrease of temperature does not change them.

Actually all synthesized nitrogen-containing compounds have a bad solubility in water. All carbazolines, esters, cationic fats and amides are insoluble in water. RT3 and R-1 are over the water layer, other carbazolines form the bottom layer. OT, OT-2, RT-3, R-1, RB and RT-2 form emulsions under stirring. At heating their solubility slightly increases; at $323 \mathrm{~K}$ a cloud considerably decreases but does not disappear completely. At heating to $323 \mathrm{~K}$ carbazoline CD-3 forms a cloudy emulsion but SB, SB-2 and ST-4 are insoluble under such conditions. The decrease of temperature leads to formation of sludge, segregation and solutions freezing.

The addition of water to the transparent imidazoline solutions results in their cloudiness (dispersed solutions

Table 1

\begin{tabular}{|l|c|c|c|c|}
\hline \multirow{2}{*}{ Solvent } & \multicolumn{4}{|c|}{ Solubility in the solution at temperatures (K): } \\
\cline { 2 - 5 } Inhibitor base & 293 & 323 & 283 & 258 \\
\cline { 2 - 5 } Carbazoline SB & insoluble & $\begin{array}{c}\text { solvent + isopropanol+inhibitor }(4: 1: 5) \\
\text { partially soluble, } \\
\text { cloudy }\end{array}$ & $\begin{array}{c}\text { sludging, cloudy, } \\
\text { nonfreezing }\end{array}$ & $\begin{array}{c}\text { sludging, cloudy, } \\
\text { nonfreezing }\end{array}$ \\
\hline Carbazoline SB-2 & insoluble & $\begin{array}{c}\text { partially soluble, } \\
\text { cloudy }\end{array}$ & $\begin{array}{c}\text { sludging, cloudy, } \\
\text { nonfreezing }\end{array}$ & $\begin{array}{c}\text { sludging, cloudy, } \\
\text { nonfreezing }\end{array}$ \\
\hline Carbazoline SD-3 & insoluble & $\begin{array}{c}\text { partially soluble, } \\
\text { cloudy }\end{array}$ & $\begin{array}{c}\text { sludging, cloudy, } \\
\text { nonfreezing }\end{array}$ & $\begin{array}{c}\text { sludging, cloudy, } \\
\text { nonfreezing }\end{array}$ \\
\hline Carbazoline ST-4 & insoluble & $\begin{array}{c}\text { partially soluble, } \\
\text { cloudy }\end{array}$ & $\begin{array}{c}\text { sludging, cloudy, } \\
\text { nonfreezing }\end{array}$ & $\begin{array}{c}\text { sludging, cloudy, } \\
\text { nonfreezing }\end{array}$ \\
\hline Carbazoline OB & soluble & soluble & transparent & nonfreezing \\
\hline Carbazoline OD-3 & soluble & soluble & transparent & nonfreezing \\
\hline Carbazoline OT-2 & soluble & soluble & transparent & nonfreezing \\
\hline Carbazoline RB & soluble & soluble & transparent & nonfreezing \\
\hline Carbazoline RT-2 & soluble & soluble & transparent & nonfreezing \\
\hline Cationic fat R-1 & soluble & soluble & transparent & nonfreezing \\
\hline Cationic fat RT-3 & soluble & soluble & transparent & nonfreezing \\
\hline APANA & soluble & soluble & transparent & nonfreezing \\
\hline
\end{tabular}




\begin{tabular}{|c|c|c|c|c|}
\hline \multirow[b]{3}{*}{ Inhibitor base } & \multicolumn{4}{|c|}{ Solubility in the solution at temperatures (K): } \\
\hline & \multicolumn{4}{|c|}{ jet fuel + isopropanol+inhibitor $(4: 1: 5)$} \\
\hline & 293 & 323 & 283 & 258 \\
\hline Carbazoline SB & insoluble & insoluble & - & - \\
\hline Carbazoline SB-2 & insoluble & insoluble & - & - \\
\hline Carbazoline SD-3 & insoluble & insoluble & - & - \\
\hline Carbazoline ST-4 & insoluble & insoluble & - & - \\
\hline Carbazoline OB & soluble & soluble & transparent & nonfreezing \\
\hline Carbazoline OD-3 & soluble & soluble & transparent & nonfreezing \\
\hline Carbazoline OT-2 & soluble & soluble & transparent & nonfreezing \\
\hline Carbazoline RB & soluble & soluble & transparent & nonfreezing \\
\hline Carbazoline RT-2 & soluble & soluble & transparent & nonfreezing \\
\hline Cationic fat R-1 & soluble & soluble & transparent & nonfreezing \\
\hline Cationic fat RT-3 & soluble & soluble & transparent & nonfreezing \\
\hline APANA & soluble & soluble & transparent & nonfreezing \\
\hline
\end{tabular}

are formed). At the decrease of temperature to $283 \mathrm{~K}$ segregation followed by freezing is observed.

To increase the solubility of investigated substances we studied their solubility in double solvents $(\%)$ : water + isopropanol $(40+10)$; solvent + isopropanol $(40+10)$ (Table 1) and jet fuel + isopropanol $(40+10)$ (Table 2). The addition of isopropanol improves solubility of nitrogencontaining products in mentioned solvents (except water, therefore these experimental data are not mentioned here) and decreases the freezing temperature. This fact will give the possibility to use the inhibitor at low temperatures.

Experimental results concerning determination of protective properties of investigated nitrogen-containing compounds will be presented in the following papers.

\section{Conclusions}

1. The solubility of nitrogen-containing substances has been determined in polar and non-polar solvents, namely in oil fractions, monohydric alcohols and water.

2. It has been established that solubility of investigated substances depends upon solvent nature, its polarity, molecular mass and freezing point. The majority of investigated products are better dissolved in the polar solvent (solvent, white spirit, toluene, isopropanol). At the same time the formed transparent solvents do not freese at low temperatures.

3. It has also been established that chemical composition of investigated substances considerably affects their solubility. Thus, carbazolines based on unsaturated oleic acid have better solubility compared with those based on saturated stearic acid, as well as esters of bur oil acids, cationic fats and amides of polyaminonaphthenic acids. At the same time polar solvents better dissolve oxyethylated products with greater oxyethylation degree and non-polar solvents - products with less oxyethylation degree.
4. For the following investigations on the basis of solubility results we have selected such corrosion inhibitors as carbazolines SD-3, OT-2, cationic fat R-1 and amides of polyaminonaphthenic acids. Protective ability of mentioned inhibitors in different corrosive media under different conditions will be presented in the next paper.

5. Solvent has been selected as a solvent for further investigations.

\section{References}

[1] Sukhotin A., Shreider A. and Archakov Yu. (Eds.): Korosia i Zashchita Khimicheskoi Aparatury. Khimiya, Leningrad 1974, 9. [2] Archakov Yu. and Sukhotin A. (Eds.): Korozionnaya Stoikost Oborudovania Khimicheskyh Proizvodstv. Khimiya, Leningrad 1990.

[3] Aspel N., Volyanuk B., Teslya B. and Tyshkevych L.: Neftepererab. i Neftekhim., 1983, 4, 5.

[4] Fryazinov V., Efimova A., Umutbaev V. and Sapognikova E.: Ekspluatacia, Modernizacia i Remont Oborudovaniya, 1979, 4, 14.

[5] Bragman G. Ingibitory Korosii. Khimiya, Moskwa 1966.

[6] Topilnytsky P. and Romanchuk V.: Khimicheskaya Technika, 2008, 11, 33.

\section{ДОСЛІДЖЕННЯ РЕАГЕНТІВ РІЗНОГО ХІМІЧНОГО СКЛАДУ ДЛЯ ЗАХИСТУ НАФТОЗАВОДСЬКОГО ОБЛАДНАННЯ УСТАНОВОК ПЕРВИННОӦ ПЕРЕРОБКИНАФТИ}

Анотація: Наведено результати дослідження розчинності азотвмісних речовин в полярних та неполярних розчинниках, низькотемпературні властивості отриманих розчинів та дослідження їх антикорозійних властивостей як інгібіторів корозії у двофазній системі вуглеводень-вода.

Ключові слова: корозія, захист від корозії, інгібітори корозії, карбазоліни, розчинники, розчинність. 